\title{
SENTIMENT ANALYSIS OF CUSTOMER FEEDBACK ON APPAREL AND COSMETICS PURCHASE IN E-COMMERCE: A TAKE ON CUSTOMER SATISFACTION
}

\author{
SUKESH MARLA ${ }^{1}$ \\ ${ }^{1}$ SYMBIOSIS INSTITUTE OF BUSINESS MANAGEMENT, BENGALURU.
}

\begin{abstract}
Customer Satisfaction has been the major driving factor for the revenue generation for any company especially those are operating in the Ecommerce domain. In this research, the consumer perception across various factors was considered especially the ones which impact the customer satisfaction in Ecommerce domain. Primary data has been collected in the form of questionnaire to know the most important factors that are responsible for better customer satisfaction.

From the factors which has impacted more, secondary data in the form of reviews are collected for every factor and Sentiment Analysis is performed to understand the perception of customers and their level of satisfaction with the overall service This will help the firms to gain a sneak peek into the satisfaction levels of the customer and the kind of experience they have or would like to have.
\end{abstract}

Keyword: Customer Satisfaction, Quality, E-commerce, Delivery, Return and Refund, Reverse Logistics, Perception, Sentiment, Ease of ordering, Supply Chain.

\section{Introduction}

Customer perception is one of the most important aspect to know whether a particular product/ service is creating the Actual value that it was Envisioned for. It helps the leadership to decide on the strategies to improve the value that is being delivered and hence ensure better Profitability and a sustainable competitive advantage by addressing the challenges that come in way of ensuring a delightful experience to the customer.

Needless to say, E-commerce has opened up ever expanding horizons in every category that could we imagine of and the players in the segment have been persistent in improving the customer experience to gain higher market share.

Apparels and Cosmetics are the categories that goes hand in glove. Coming to the Cosmetics, it is in the nascent stage of this boom in E commerce presenting the managers with its own opportunities and challenges in the Supply chain which have an impact on the various aspects of customer satisfaction by the service.

Offline shopping still rules in case of cosmetics industry. Out of the total revenue, the share of ecommerce is merely $5 \%$ which shows that the ecommerce space is fairly unexplored.
Whereas the Global Fashion and Apparel Ecommerce market is well established and is expected to grow at a compounded growth rate of $10.6 \%$ and the world-wide revenue is projected to touch 713 Billion Dollars.

This research will study the existing challenges in the supply chain which is hindering the players in this category to provide a superior customer experience and hence drive more sales and growth.

After getting to know the perception of the customer in many aspects like Delivery Charges, Delivery Quality, Availability of the items, Ease of placing order, Pricing, Effectiveness of Marketing and advertising, Loyalty programs, Returns processing from the primary data source and hence do the regression to get the important factors that are critically impacting the Customer satisfaction.

Based on the factors that are significant from the regression the reviews and opinions of the consumers across various ecommerce sites are collected and a Sentiment analysis of the same will be conducted to find the exact customer perception. The conclusions will be drawn as to how the players in the category are performing in each of the aspects mentioned above and map the dissatisfaction of the customers with the existing challenged in the supply chain which are causing this dissatisfaction.

Post this, the focus would shift to apply the existing technological and managerial solutions to solve the identified challenges through sentimental analysis and hence ensure an effective supply chain which provides a delightful customer experience and increased profitability to the player. 
REV

\section{IEW OF LITERATURE:}

With the penetration of internet in every part of the country, the Ecommerce purchases have grown exponentially. Due to the pandemic, there has been an exponential rise in the sales especially through the Ecommerce market. Customers are getting accustomed to the ecommerce sites. The sales on these sites are phenomenal and the global apparel ecommerce market is growing at a CAGR of $10.6 \%$, which makes the customer satisfaction vital to them.

Ecommerce has become a buzzword, due to three important factors, internet penetration, effective and efficient way of communication and the ability to capture information and personalise according to the needs of the consumer. Here in the study, the focus has been on the customer satisfaction which is the heart of the business. The customer satisfaction can be defined as the ability of the firm or the product to satisfy the customer throughout the journey of the order. This has been discussed across organizations, and attempt to measure the customer satisfaction.

The concept study on psychological reactions to the customer satisfaction with e-shoppers has been explained well by Begam, M.S. (PSYCHOLOGICAL REACTIONS TO THE CONSUMPTION EXPERIENCE OF ONLINE SHOPPERS WITH E-COMMERCE, 2020) through applying two factor theory taking hygiene factor and motivation factor while calculating the customer satisfaction.

According to (Kshetri, 2007), the Ecommerce business profitability is affected by the barriers such as Economic, socio-political and Cognitive factors where as in our study, we are focusing mostly on customer satisfaction showing that the firm's profitability is dependent on it. Author Kshetri N, as defined in (Barriers to e-commerce and competitive business models in developing countries: A case study. Electronic commerce research and applications, 2007) that the ecommerce to succeed, the cognitive barriers play a predominant role. He also created a model on how these barriers influenced the Ecommerce business and this can be shown using the below figure. His study talked about the developing countries, as we are studying the same for India, his study marks significance.

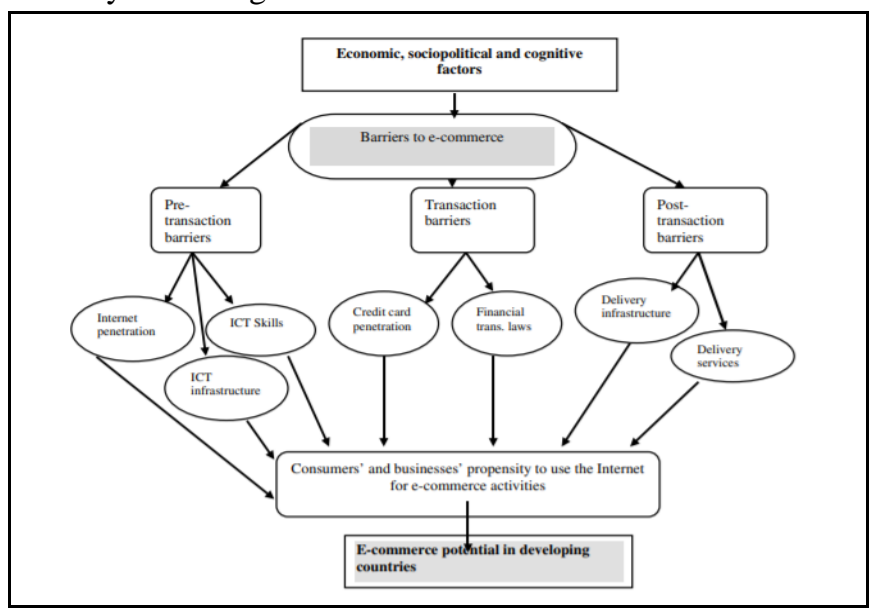

Fig 1

Customer Satisfaction is often a thin line between what customer needs and what a firm perceives, as indicated by (Lin, 2003) and he also states that the importance of the customer satisfaction has inadvertently increased due to the faster internet and the less costly platform for the business. He stated that the ecommerce firm is accountable to its customers for the delivery of the product and quality of the product. And he had explained the ecommerce function is a value chain with primary activities and the support activities performed equally. And as per the study (An empirical study of perceived factors affecting customer satisfaction to re-purchase intention in online stores in China., 2015) which is limited to China, defined that the customer experience/ satisfaction is dependent on seven factors Price, Product performance risk, Product information, Financial Risk, Delivery, Return, Ease of ordering. Using these factors, the study has calculated the customer satisfaction which is responsible for the customers to repurchase.

A study by an author (Kok, 2017) on reverse logistics around the Klang valley in Malaysia which determines the relationship between variables of situational factors and customer satisfaction towards the reverse logistics as shown in the below research framework.

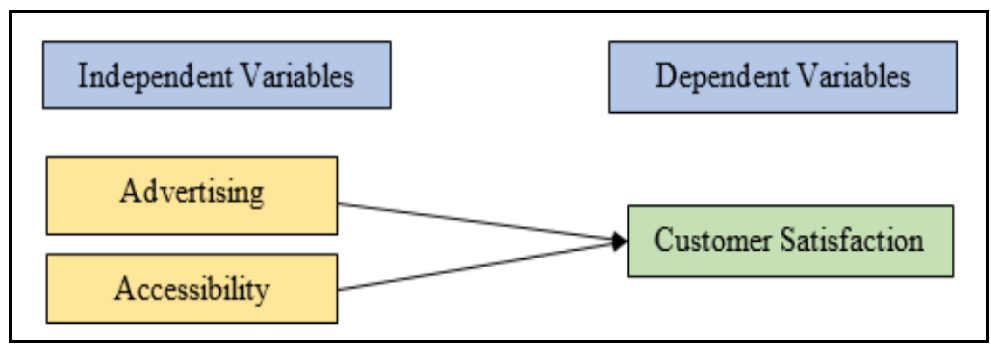

Fig 2

\section{Literature Gap:}

The existing studies have been focussed upon the supply side challenges that hinders the smooth functioning of the business like Higher Operating losses, Poor inventory management, Changing market trends, Market Penetration, Consumer behaviour. There are studies which focussed on the customer satisfaction, but limited to certain country and with the intention of calculating the repurchase intention of the consumer.

There is no detailed study on the Customer perception towards the aforementioned aspects and the related challenges in the supply chain which are causing dissatisfaction to the customer hence impacting their perception towards shopping for Apparel and Cosmetics online.

Here we are making an attempt to combine two of these explored areas and incorporate a study, which determines the factors affecting the customer experience as well as identifying the supply chain challenges that are hindering the customer experience.

Given the fact that there is going to be increased penetration of E commerce as a proportion to the total Apparel and 
Ecom merce sales as more and more people are brought into the digital ecosystem, it is important for the players in the market to know the customer perception and make the supply chain effective enough to provide a robust supply chain which would help the firms in Customer acquisition and Retention.

\section{RESEARCH METHODOLOGY:}

\section{Conceptual Framework:}

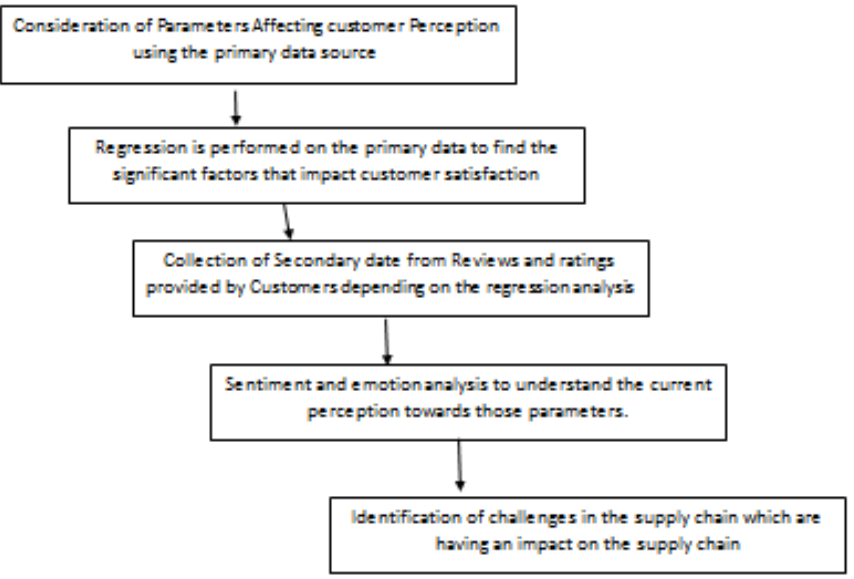

\section{Data collection:}

Data collection has been done in two phases.

In the first phase, Primary data has been collected through a questionnaire. The questionnaire has been prepared by considering the different factors such as Delivery Charges, Delivery Quality, Availability of the items, Ease of placing order, Pricing, the Effectiveness of Marketing and advertising, Loyalty programs, Returns processing. The sampling technique used here is convenient sampling. The data collected has 262 responses from the millennial population who are into these Ecommerce shopping.

Based on the output from the regression, the second phase of the data collection is started. In phase two, Secondary data has been collected from various sites and application sources where customers give their reviews and ratings to the online channels from which they make the purchase. The data has

\begin{tabular}{|l|l|l|l|l|l|l|}
\hline Independent Variables & Delivery & Quality & $\begin{array}{l}\text { Packaging of } \\
\text { the order }\end{array}$ & $\begin{array}{l}\text { Ease of } \\
\text { Ordering }\end{array}$ & $\begin{array}{l}\text { Returns and } \\
\text { Refund }\end{array}$ & $\begin{array}{l}\text { Customer } \\
\text { Service }\end{array}$ \\
\hline Delivery & 1 & & & & & \\
\hline Quality & 0.2226335 & 1 & & & & \\
\hline Packaging of the order & 0.2651817 & 0.226088 & 1 & & & \\
\hline Ease of Ordering & 0.0337135 & 0.460992 & 0.252088715 & 1 & & \\
\hline Returns and Refund & 0.3627899 & 0.16715 & 0.13209168 & 0.215858 & 1 & 1 \\
\hline Customer Service & 0.2044037 & 0.194837 & 0.210615578 & 0.197189 & 0.29466928 & \\
\hline
\end{tabular}

Table 1 been collected from the respective websites, newspapers, blogs and articles which focuses mostly on the Ecommerce Business. More than hundred reviews have been collected for the textual analysis for every factor and 600 plus reviews for the independent factor. The reviews are carefully segregated and collected giving consideration to the aspects that have been mentioned above ranging from the effectiveness of the delivery to the quality of the products which have been significant from the regression that was done. Also, the secondary data has been used to identify the issues in the supply chain.

\section{Statistical techniques:}

Correlation was performed on the variables (factors impacting customer satisfaction) that were collected using the primary data and the variables are checked for any strong correlation between those variables which are dependent variables in the regression. Once after the correlation details are tabulated the data has been cleaned for regression.

Multi - Variate Regression was performed on the data that was collected from the primary source after cleaning and normalisation of the data.

Sentiment and Emotion analysis was done on the secondary data that was collected from the websites of the Ecommerce platforms, articles and blogs. Sentiment and Emotion Analysis was done using $\mathrm{R}$ programming with emotional lexicon covering 10 emotions and Bing Classification of sentiment Analysis with overall mean sentiment score.

\section{Variables:}

We have considered 5 variables that were independent of each (Loosely correlated) and one dependent variable.

Independent Variables are Quality, Packaging, Ease of ordering, Returns and Refund and Customer Service. Dependent variable is the customer satisfaction.

\section{Analysis:}

\section{Correlation of the independent variables:}




\section{Base - Customer Service}

$\mathrm{d}$ on the questionnaire the customer satisfaction is impacted by the factors such as Delivery Charges, Delivery Quality, Availability of the items, Ease of ordering, Pricing, Effectiveness of Marketing and advertising, Loyalty programs, Returns processing, Customer service. But on taking the correlation between these variables all the factors are not significant rather impacting the customer service. The factors that are significant enough are

- Delivery

- Quality

- Packaging of the order

- Ease of Ordering

- Returns and Refund
Based on the correlation data, the above factors are independent of each other which makes these variables the perfect fit to develop the model. From the correlation analysis we can see that the correlation between the any two variables is less than 0.5 which shows that the factors are not strongly correlated.

\section{Empirical model:}

With the factors mentioned above being the independent variables and Customer satisfaction being the dependent variable the empirical model from regression will look like the following:

Customer Satisfaction $=\alpha+{ }^{\beta} 0($ Quality $)+{ }^{\beta 1}$ (Returns and Refunds) $+{ }^{\beta 2}$ (Ease of ordering) $+{ }^{\beta 3}$ (Packaging) $+{ }^{\beta 4}$ (Customer Service)

\section{Multi- variate regression:}

Multi Variate Regression was performed on the primary data that was collected after normalising and cleaning the data, considering the variables that are not strongly correlated in as the independent variables. The model is built on 5 independent variables with customer satisfaction being the independent variable. The model has been built using $\mathrm{R}$ programming and the model is shown below:

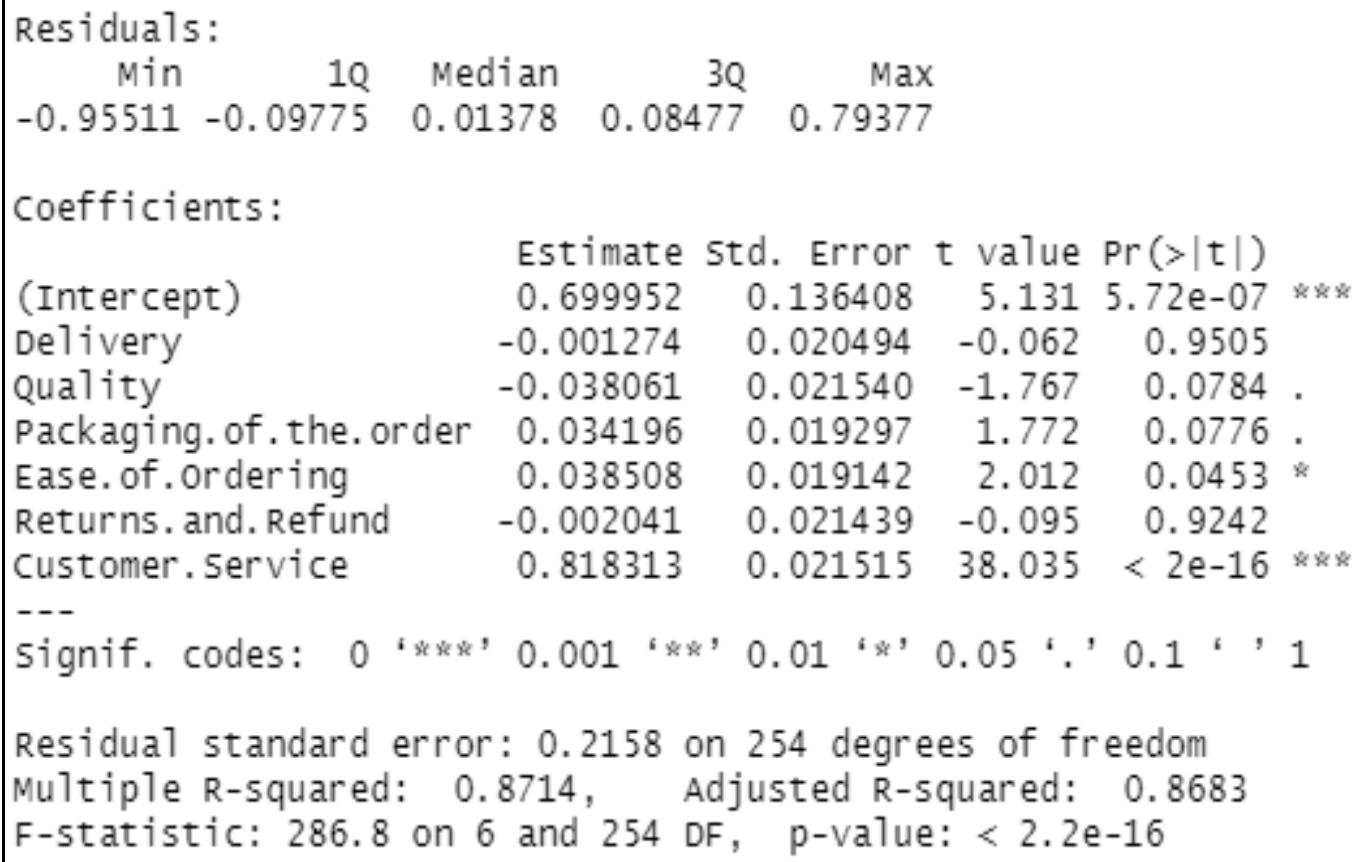

Fig 3

From the model built using $\mathrm{R}$, we can see that the $\mathrm{R}$ square and Adjusted R Square are more than $85 \%$, which makes the model a good fit. The factors Customer Service, Ease of ordering, Packaging of the order and Quality are significant at $95 \%$ confidence interval.

The model has been trained and tested on the different data which resulted in the accuracy of $63.5 \%$, though there is a scope for improvement here, but the accuracy and precision are consistent. The accuracy can be seen in the below matrix. Here the variables "actuals" are taken from the test data's dependant variable whereas the "predicteds" are calculated from the model generated using training data. The accuracy of the model can be improved by adding intricate variables.

\begin{tabular}{|lrr|}
\hline & actua7s & predicteds \\
actua7s & 1.000000 & 0.634894 \\
predicteds & 0.634894 & 1.000000 \\
\hline
\end{tabular}

Fig 4

Sentiment and emotion trend analysis:

Sentiment:

From the correlation matrix and the regression model, reviews are collected from the articles, blogs and online ecommerce sites for the above

ISSN (Print): 2204-0595

ISSN (Online): 2203-1731 
on significant variables.

Sentiment Analysis is performed to understand the perception of customers and their level of satisfaction with the overall service and individual aspects like delivery, pricing, ease of placing order and quality of the product etc. This will help the firms to gain a sneak peek into the satisfaction levels of the menti customer and the kind of experience they have or would like to have.

The data collected for the different aspects impacting the customer satisfaction along with the overall customer satisfaction showed the positive sentiment and for all the factors the sentiment is positive in online purchase of apparels and cosmetics.

\begin{tabular}{|l|l|l|l|}
\hline Data & Negative & Positive & Sentiment \\
\hline Customer Service & 413 & 499 & 86 \\
\hline Delivery & 156 & 530 & 374 \\
\hline Ease of Ordering & 298 & 414 & 116 \\
\hline Packaging & 164 & 393 & 229 \\
\hline Quality & 192 & 321 & 129 \\
\hline Returns \& Refund & 224 & 336 & 112 \\
\hline Customer Satisfaction & 865 & 1565 & 700 \\
\hline
\end{tabular}

Table 2

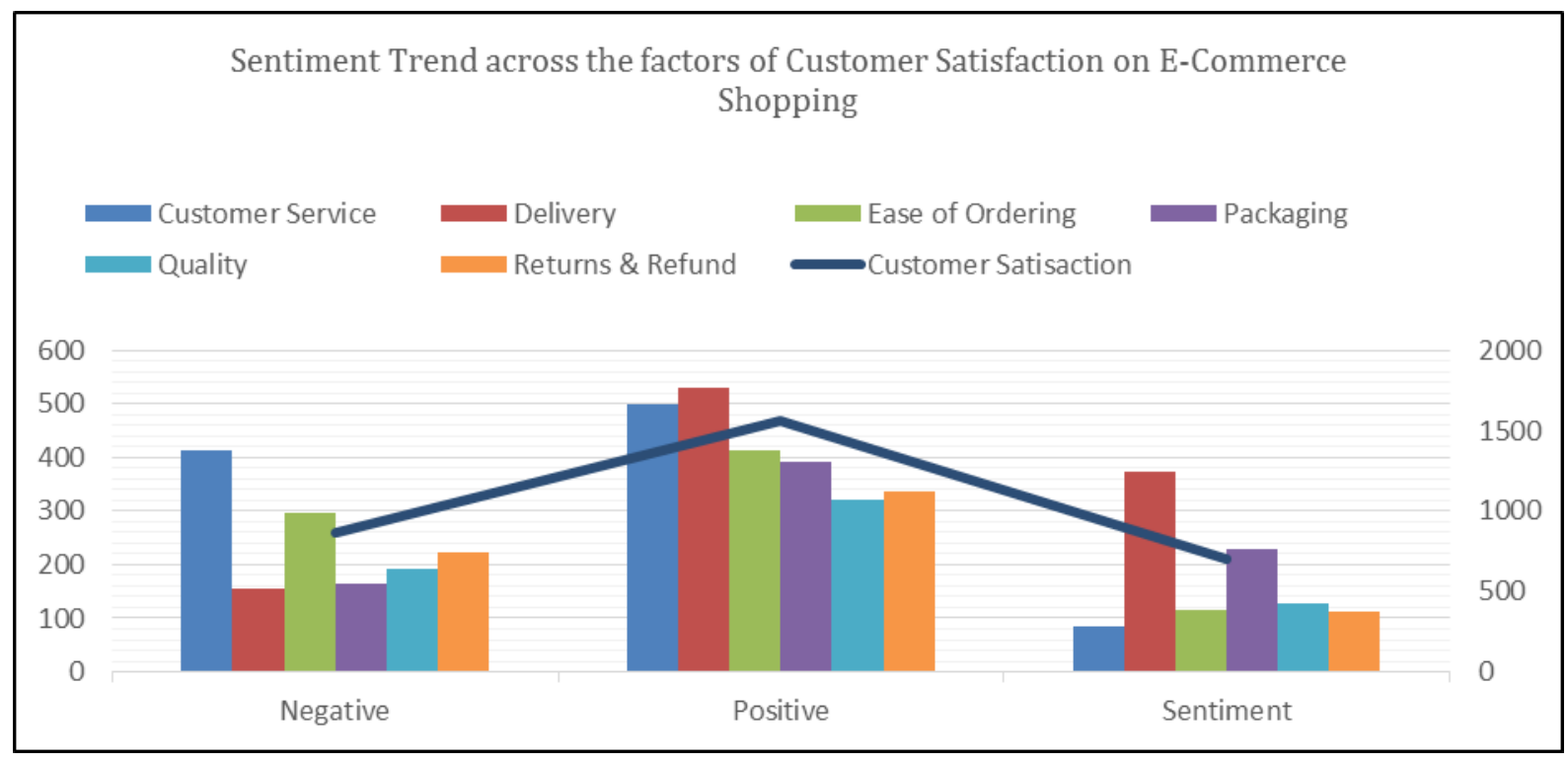

Graph 1

The overall sentiment score for Delivery and Packaging is fairly decent which shows that the customer has a positive attitude towards these factors. A positive attitude towards these factors implies that the delivery rates are better and the packaging was intact and usage of better materials made the package can withstand all the jerks and pressures while delivery. The distribution strategies are robust and are working effectively which has improved the customer perception towards these factors.

The Ecommerce sites have been consistently scoring low on sentiment with respect to Quality and Customer Service. As per the research objectives, the supply chain challenges are to be identified to highlight the low score in these areas. Quality has been impacted due to the
Customer Service is pivotal for an online commerce firm since the involvement of the customer in the journey is quite little. The time-to-time updates about the order and the responsiveness of the customer service agent has to be given higher priority and the requests from the customer have to be handled quite efficiently. The reverse logistics has been the most hit factor for the E-commerce and the customer service is highly impacted, which has to be developed exponentially.

\section{Emotion:}

Among all the factors considered, the emotion analysis helps us derive the emotion that the customers exhibit towards the service and their perception towards each factor that has been considered here. 
This is measured in the terms of Anger, Anticipation, Disgust, Fear, Joy, sadness, surprise and trust. This is a mix of positive and negative emotions.

While this isn't like Bing classification where the positive and negative sentiment is calculated, but here in emotional analysis, the value for any emotion indicates the number of words used by the customers in the review expressing a certain emotion.

Let us say, if the emotion disgust has a value of 40, it means the number of words expressing the perception of being disgusting is 40 .

The more the value for emotions expressing a positive emotion, the better for the $\mathrm{E}$ Retailer. In the emotional Lexicon considered for this study, Joy, Surprise and Trust depict positive emotions, and Anger, Disgust, fear and sadness are the ones depicting negative emotions.

From the table one can see that the level of trust in returns and refunds as well as the quality is the least. There are certain challenges which are related to supply chain that are to be handled in order to improve the sentiment and emotion score of these factors.

Now looking at the Customer service, there are certain positive emotions but, the negative emotions overweigh them. The level of disgust, sadness, fear and negativity are highest when compared to the others, which is an issue to look out. The customer service hasn't been efficient and seamless for the buyers is what we can infer.

The emotions are positive and are decent enough when we look at the negative emotions for Ease of ordering and packaging as the usage of advanced technologies for ordering ease and usage of better materials to deliver damage free items has made the customer experience seamless with respect to these factors. The below tabular output and the Graph shows the kind of emotions existing in the collected pool of factors from the reviews.

\begin{tabular}{|c|c|c|c|c|c|c|c|c|c|c|}
\hline Data & Anger & Anticipation & Disgust & Fear & Joy & Negative & Positive & Sadness & Surprise & Trust \\
\hline $\begin{array}{l}\text { Customer } \\
\text { Service }\end{array}$ & 100 & 529 & 117 & 100 & 251 & 321 & 851 & 196 & 158 & 221 \\
\hline Delivery & 61 & 512 & 24 & 44 & 256 & 135 & 630 & 55 & 190 & 368 \\
\hline $\begin{array}{ll}\text { Ease } & \text { of } \\
\text { Ordering } & \end{array}$ & 87 & 356 & 40 & 41 & 216 & 159 & 495 & 49 & 135 & 345 \\
\hline Packaging & 52 & 322 & 37 & 44 & 174 & 136 & 481 & 69 & 114 & 268 \\
\hline Quality & 57 & 311 & 53 & 47 & 153 & 151 & 458 & 79 & 102 & 245 \\
\hline $\begin{array}{l}\text { Returns \& } \\
\text { Refund }\end{array}$ & 45 & 258 & 24 & 35 & 155 & 106 & 404 & 53 & 101 & 242 \\
\hline $\begin{array}{l}\text { Customer } \\
\text { Satisfaction }\end{array}$ & 246 & 1392 & 221 & 215 & 747 & 694 & 2167 & 381 & 489 & 1177 \\
\hline
\end{tabular}

Table 3 


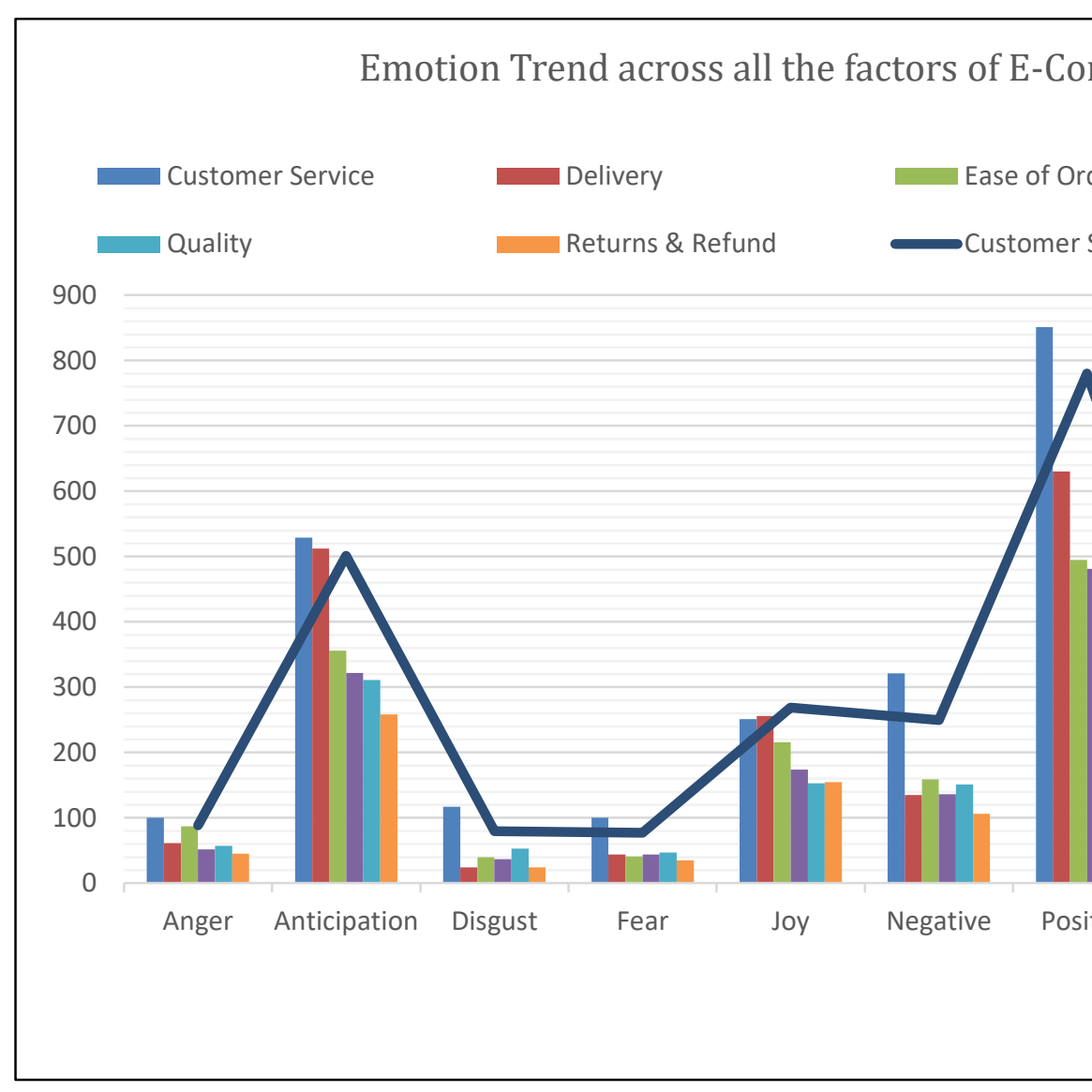

\section{RESULTS AND DISCUSSION:}

\section{Identification of Challenges in the Supply Chain:}

The Challenges in the supply chain are identified by the sentiment analysis on the factors that are impacting the customer perception. From the sentiment analysis, Customer Service, Returns and refunds, Quality and Ease of Ordering are low on sentiment score. Though the sentiment is positive, when compared to the other factors on the sentiment score the mentioned factors scores low. This perception can be considered as neutral and this doesn't do well with the firm that is aiming at customer retention and acquisition to get a loyal customer base, since the customers switch to competitors easily as there is no switching cost involved.

A neutral perception will never help in customer retention, it happens only when a customer's needs are satisfied every time and a delightful shopping experience is provided to them at all levels and at all times. Hence it should be in the priority list of the firms to proactively act on factors which is leading to a negative or a neutral perception among the customers. By Addressing each factor causing an unfavourable perception, we try to identify the challenges existing in the supply chain that is causing dissatisfaction to the customer.

Returns and refunds: By looking at the results arrived at, it is evident that the returns and refunds carry a very low sentiment score which is below par when compared to other factors. This shows that the customers are not satisfied with the returns and refunds policies and procedures. From the data available and
Graph 2

studying the trends in the industry, it is identified that challenges in reverse logistics exist which are making it difficult to the customers to return the products that have not met the specifications or their satisfaction levels.

Challenges exist such as slots being unavailable according to the convenient timings of the customers to be present and return the product to the delivery executive and customer service executives not accepting genuine complaints from the customers to approve the returns.

Some striking challenges in the refund policies and procedures are such that in case of failure of payment due to various reasons like payment gateway failure, technology failure, the funds are debited from the customer's account and it takes to the tune of 5 to 7 days to complete the refund process due to multiple underlying interfaces with dependencies on payment gateways, banks etc. Efforts should be made to have a robust reverse logistics system in place and usage of effective platforms and gateways wherein the failure rates are low and processing of refunds are comparatively quicker.

Quality: While aspects like ease of ordering, quick deliveries provide the aesthetic value required to acquire and retain customers, it is the quality of the commodities purchased which is very basic and of utmost importance to the customer. In many cases, the quality is compromised in the products like the customers complaining about receiving items which are past their date of expiry (in cosmetics), missing items in the order, poor packaging causing damage to the products etc. 
With effective inventory management, timely deliveries and keeping in check the date of expiry of the products and full order fulfillment with proper supervisory tools and process supported by automated tools and machines, such issues of quality can be avoided.

Customer Service: Along with the flow of goods, something which is imperative in having a successful supply chain is effective flow of information and having right people at right positions to ensure best possible capabilities for the firm. Customer service is the single point of contact available to the customers and any compromise or laxity in ensuring a superior customer service is bound to cost dearly to the Ecommerce since the consumer involvement is minimal. Some of the challenges in customer service are longer waiting times before connecting to an executive, insufficient information or poor customer handling by the customer service personnel, ineffective and primitive chatbots etc. Such challenges increase the displeasure of the customer who is already dissatisfied with his purchase and is trying to approach the customer service as a redressal platform. Some remedial measures to be taken here are effective training, development and performance tracking initiatives to the customer service executives so that they put into practice the best acquired skills and practices while they serve the customers with consistent, sufficient information and support without any gaps in communication.

The above are the challenges identified in the supply chain which cause low sentiment or neutral perception among the customers in factors Quality, Customer service and Returns and refunds.

\section{CONCLUSION:}

The objectives of the study were achieved by applying the statistical techniques such as Regression, Correlation Analysis on the primary data that was collected by determining the factors that impact the Customer Experience (Satisfaction). Then the secondary data is collected in the form of reviews, after finalising the factors which impact the customer experience critically, from the regression output. After analysing the mind of the consumer and understanding their needs through reviews, we have identified certain challenges across the supply chain ranging from Sourcing, Production, Packaging, Inventory and Logistics which are having an impact on the customer satisfaction.

The study (Sentiment Analysis), helped in identifying the factors that carry negative and neutral sentiment with respect to the customer experience which in-turn carry the risk of customer switching from one Ecommerce site to other. In addition to that, the emotion and sentiment study helped in understanding the customer perception towards the online purchasing and the challenges they face during the course of the purchase.
With the absence of improvement in the factors which carry negative sentiment will not bode well to the customer acquisition and retention strategies which is the core aim in the Ecommerce Business.

After identifying the factors that are in negative sentiment space of the customer, the study has concentrated on finding the existing challenges in supply chain that are responsible for this unfavourable sentiment.

The gaps in the supply chain that are responsible for negative sentiment or low sentiment score are to be effectively filled through effective usage of technology in end-to-end management of goods, information and people. Ecommerce in Apparels and Cosmetics space will be able to achieve superior customer satisfaction levels that attracts more sales which makes the firm profitable and gives it a sustainable competitive advantage over others.

There is a scope for future study into this space as well. The study was done effectively to identify the factors influencing customer sentiment. The list of these variables is quite exhaustive and considering these too will help gauge the customer perception better. Also, not just stopping with identifying the challenges existing in the supply chain which is causing an unfavourable perception, this study can be further taken forward by including stakeholders like in-house brands, premium brands, local manufacturers, seasonal sale replenishment, aspiring entrepreneur, founders and managers of Ecommerce firms to identify and formulate solutions to counter these challenges and make these platforms more robust and customer friendly.

\section{REFERENCES:}

[1]. Kshetri, N. (2007). Barriers to e-commerce and competitive business models in developing countries: A case study. Electronic commerce research and applications, 6(4), 443-452.

[2]. Begam, M. S. PSYCHOLOGICAL REACTIONS TO THE CONSUMPTION EXPERIENCE OF ONLINE SHOPPERS WITH E-COMMERCE.

[3]. Lin, C. C. (2003). A critical appraisal of customer satisfaction and e-commerce. Managerial Auditing Journal.

[4]. Hamidi, H., \& Moradi, S. (2017). Analysis of consideration of security parameters by vendors on trust and customer satisfaction in e-commerce. Journal of Global Information Management (JGIM), 25(4), 32-45.

[5]. Lin, H. F. (2007). The impact of website quality dimensions on customer satisfaction in the B2C ecommerce context. Total Quality Management and Business Excellence, 18(4), 363-378.

[6]. Jalil, E. E. A. (2019, December). CUSTOMER SATISFACTION AND REVERSE LOGISTICS IN E-COMMERCE: THE CASE OF KLANG VALLE

ISSN (Print): 2204-0595 ISSN (Online): 2203-1731 
. In Proceedings of the 9th International Conference on Operations and Supply Chain Management, Ho Chi Minh City, Vietnam (pp. 15-18).

[7]. Oliver, R. L. (2014). Satisfaction: A behavioral perspective on the consumer: A behavioral perspective on the consumer. Routledge.

[8]. Rao, S., Lee, K. B., Connelly, B., \& Iyengar, D. (2018). Return time leniency in online retail: a signaling theory perspective on buying outcomes. Decision Sciences, 49(2), 275-305.

[9]. Kok, C. C., Siew, S. L., Hoe, C. Y., \& A Jalil, E. E. (2017). The importance of logistics competencies towards online shopping behaviour among university students.

[10]. Yu, Y., Wang, X., Zhong, R. Y., \& Huang, G. Q. (2017). E-commerce logistics in supply chain management. Industrial Management \& Data Systems.

[11]. Nisar, T. M., \& Prabhakar, G. (2017). What factors determine e-satisfaction and consumer spending in e-commerce retailing? Journal of retailing and consumer services, 39, 135-144.

[12]. Nguyen, H. T. (2014). Factors Affecting Customer SatisFection and Trust in an E-commerce setting: a Case Study of Muachung. vn in Vietnam. AU-GSB e-JOURNAL, 7(1).

[13]. Conor Gallagher, E. F. (2019). The Application of Sentiment Analysis and Text Analytics to Customer Experience Reviews to Understand What Customers Are Really Saying. International Journal of Data Warehousing and Mining (IJDWM), 27. 16.

[14]. San Lim, Y., Heng, P. C., Ng, T. H., \& Cheah, C. S. N. Anubhav Reddy, B. R. (2014). A Stu (2016). Customers' online website satisfaction in online apparel purchase: A study of Generation $\mathrm{Y}$ in Malaysia. Asia Pacific Management Review, 21(2), 74-78

[15]. Escobar-Rodríguez, T., \& Bonsón-Fernández, R. (2017). Analysing online purchase intention in Spain: fashion e-commerce. Information Systems and e-Business Management, 15(3), 599-622.

[16]. planned behavior. Journal of Cleaner Production, 732-739.

[17]. Zhang, B., Fu, Z., Huang, J., Wang, J., Xu, S., \& Zhang, L. (2018). Consumers' perceptions, purchase intention, and willingness to pay a premium price for safe vegetables: A case study of Beijing, China. Journal of Cleaner Production Volume 197, Part 1, 1498-1507. 